\title{
EFFECTS OF MAINTAINING DIFFERENT BODY POSITIONS ON ATTENTIONAL ALLOCATION OF OBESE AND NON-OBESE WOMEN
}

\author{
Fernando Garbeloto dos Santos ${ }^{1}$, Umberto Cesar Côrrea ${ }^{1}$, Ricardo Drews ${ }^{2}$, \\ Go Tani $^{1}$, and Flavio Henrique Bastos ${ }^{1}$ \\ ${ }^{1}$ School of Physical Education and Sport, University of São Paulo, São Paulo, Brazil \\ ${ }^{2}$ Faculty of Physical Education and Physiotherapy, Federal University of Uberlândia, Brazil
}

Original scientific paper

DOI: $10.26582 / \mathrm{k} .51 .2 .16$

\begin{abstract}
:
Studies have shown that obese individuals may require more attentional resources to perform postural control compared to non-obese individuals. However, it is unclear if this difference in the allocation of attention can only be observed in body positions that lead to a higher level of instability. The objective of this study was to investigate if obesity affects the allocation of attention for maintaining body postures with different levels of balance demand. Ten obese women $(\mathrm{BMI}=41.7 \pm 8.5)$ and ten non-obese women $(\mathrm{BMI}=21.8 \pm 1.3)$ volunteers were assigned into two groups $(\mathrm{M}$ age $=39.7 \pm 7.6)$ : obese and eutrophic. The visual reaction time simultaneous with the maintenance of the body positions with different levels of balance demand (sitting, standing and unipedal stance) was used to infer the allocation of attentional resources. A longer reaction time was observed in the unipedal stance, compared to the other positions, for both groups. However, no difference was observed between the obese and eutrophic groups, for any of the body positions. The results diverge from the existing literature, showing that obesity does not affect the allocation of attention for postural control.
\end{abstract}

Key words: dual task performance, balance, reaction time

\section{Introduction}

Obese individuals are the target of growing interest from researchers all over the world. With a worldwide epidemic status, overweight and obesity are defined as abnormal or excessive fat accumulation that presents a risk to health (WHO, 2015). Specifically, a person with a BMI of $25 \mathrm{~kg} / \mathrm{m}^{2}$ or more is considered overweight, while a person with a BMI equal to or more than $30 \mathrm{~kg} / \mathrm{m}^{2}$ is considered obese (WHO, 2015). In addition to being a predictor for a number of diseases (Kopelman, 2000), some studies indicate that obese individuals, when compared to eutrophic individuals $\left(\mathrm{BMI}<25 \mathrm{~kg} / \mathrm{m}^{2}\right)$, present greater oscillation of their center of pressure, which may impair their postural control and consequently their dynamic (McGraw, McClenaghan, Williams, Dickerson, \& Ward, 2000) and static balance (Hue, et al., 2007; Teasdale, et al., 2006). A greater difficulty in maintaining the postural control may imply a greater demand for attentional resources (McNevin, Shea, $\&$ Wulf, 2003) and affect other actions carried out in daily life.

Methodologically, one way of investigating whether postural control maintenance affects the demand for attentional resources is to require participants to perform a task concurrent with this posture control - dual tasking or a dual task paradigm (Brown, Sleik, \& Winder, 2002; Lajoie, Teasdale, Bard, \& Fleury, 1993; van Dieën, Koppes, \& Twisk, 2010; Vuillerme, Isableu, \& Nougier, 2005). The tasks involving reaction time are often used as the "secondary" tasks to infer about the use of attentional resources by a "primary" task (such as maintaining posture - e.g. Lajoie, et al., 1993). In this case, an increase in reaction time, for example, indicates that some physical and/or environmental restriction is affecting the maintenance of postural control, which demands more attentional resources (Gage, Sleik, Polych, McKenzie, \& Brown, 2003; Lajoie, et al., 1993; Tucker, Kavanagh, Barrett, \& Morrison, 2008). The effect observed in the performance of the secondary task is attributed to a competition for attentional resources.

Employing the dual-task paradigm, the study carried off by Mignardot, Olivier, Promayon, and Nougier (2010) verified the effects of obesity on the need for attentional resources, for the maintenance of postural control, in sitting and monopedal support positions. In this study, a task of auditory reaction 
time was used in obese and eutrophic individuals. The results indicated that in the sitting condition the obese and eutrophic individuals presented similar reaction time. However, in the monopedal condition, the obese individuals exhibited longer reaction times than the eutrophic participants. The authors observed that obesity increased the demand for attentional resources for the maintenance of the body balance in the monopedal position.

It is important to highlight that the difference between the obese and eutrophic participants found in the Mignardot et al. (2010) study was restricted to the maintenance of balance in the monopedal support, not being observed in the sitting position. Thus, it is not clear whether this difference between the obese and eutrophic individuals can be observed in body positions with different degrees of postural instability such as a standard bipedal posture. This problem is backed up by the evidence that attention allocation for postural control varies according to the equilibrium demand, that is, the degree of posture instability (Lajoie, et al., 1993). In this sense, it is possible that obese individuals present a greater need for attentional resources only in more unstable postures, such as monopedal support, but not in the use of these resources for postural control in more stable body positions, such as the standard (bipedal) standing posture - more stable relative to the monopedal support but more unstable relative to the sitting position.

Thus, the objective of the present study was to investigate if obesity affects the attention allocation for maintaining body positions with different degrees of equilibrium demand: sitting, standing and monopedal support standing. It is expected that in less unstable body positions, relative to the single-leg support (bipedal standing and sitting positions), the demand for attentional resources to maintain postural control between the obese and eutrophic individuals is similar. However, in the monopedal position, it is expected that the obese individuals will need more attentional resources for postural control (inferred through a longer reaction time) in relation to the eutrophic individuals.

\section{Methods}

\section{Sample}

Data are presented as mean (M) and standard deviation (SD). Twenty women participated voluntarily in the study, divided into two experimental groups: OB (obese, $\mathrm{n}=10$ ) and $\mathrm{EU}$ (eutrophic, $\mathrm{n}=10$ ). Participants in the OB group presented BMI above $30 \mathrm{~kg} / \mathrm{m}^{2}(\mathrm{M}=41.7 ; \mathrm{SD}=8.5)$, were of an average age of 41 years $(\mathrm{SD}=6.6)$, and were enrolled - but had not yet begun to perform physical activities in the physical activity program Health and Wellness in Obesity, offered by the Physical Education and Sport School of the University of São Paulo.
The participants in the EU group presented BMI between 18.5 and $25 \mathrm{~kg} / \mathrm{m}^{2}(\mathrm{M}=21.8 ; \mathrm{SD}=1.3)$ and were matched to the OB group participants in sex and age $(\mathrm{M}=39.7$ years; $\mathrm{SD}=7.6)$. All participants had normal or corrected eyesight, and none had any previous experience in the employed sensorimotor task. The participation in the experiment required completion of a free and informed consent form, which detailed the research procedures and explained the participant's rights. The study was approved by the local ethics committee (CAAE 01281112.2.0000.5391).

\section{Instruments}

The equipment consisted of a 22-inch LCD monitor - set to a $1680 \times 1050$ pixels resolution and a $120 \mathrm{~Hz}$ refresh rate - and a switch, connected by a coaxial cable, to a data acquisition module (Labjack U3-HV). A PC compatible microcomputer managed the task stimuli generation and data acquisition running a script developed specifically for the present experiment. The script was developed and run using the Psychtoolbox toolbox for GNU/ Octave in a Linux operational system (Ubuntu distro, version 12.04).

The task used to measure participants' reaction time was to press the switch, as soon as possible, when a rectangle ( $12 \times 6$ centimeters) on the center of the screen changed from a bright green color to a bright red color. After pressing the button, the rectangle changed back to the original green color, and the process was repeated for five consecutive times, with a random time intervals from 1 to 4 seconds between each trial.

A Welmi weight scale (model W-200/5) was employed to determine the BMI, with $0.01 \mathrm{~m}$ body height and $0.1 \mathrm{~kg}$ body weight precision and $2 \mathrm{~m} / 200 \mathrm{~kg}$ max measuring capacity, respectively. The BMI was computed using the standard weight $(\mathrm{kg})$ divided by squared height $(\mathrm{m})$ formula.

\section{Experimental design and procedures}

Before testing, volunteers of both groups were provided with the information about procedures and the task goal ("press the switch button as soon as possible as the rectangle has changed colors"). Data collection was performed individually, with only one experimenter present, in a room prepared for this purpose.

Participants performed the task four times (five trials in each attempt). The first attempt was used to familiarize participants with the task requirements such as how to press the switch button (holding the switch box with only the preferred/dominant hand and pressing the button with the thumb) and which color change the participant should be reacting to. The following attempts were made in the seated, standing (bipedal with the feet together) and monopedal positions - five trials/single reaction times in 
each position - in a pseudo-random, counterbalanced order between the participants.

The distance from the participant's head to the monitor was about one meter during task execution, and a chair with adjustable height was employed to try to keep the participants' eyesight at about the same level during the seated condition as when upright standing. A $1 \mathrm{~m} \times 1 \mathrm{~m}$ x $2 \mathrm{~cm}$ Ethylene Vinyl Acetate mat replaced the chair in both upright positions, with participants being barefoot during testing. In the monopedal position, participants were asked to stand using only the ipsilateral feet to the dominant/preferred hand (the hand used to hold the switch) during task execution. No augmented feedback was provided to participants.

\section{Statistical analysis}

The performance measure for the simple reaction time was the recorded difference between the stimuli color change and the moment the participant pressed the switch button. The trimmed mean (R Core Development Team., 2013) - was calculated for each condition (five trials), removing 10\% of the highest and lowest values, resulting in three data points per participant.

After checking data for the assumptions of parametric tests, performance data was analyzed using a two-way ANOVA (group vs. body position) with repeated measures on the second factor. Mauchly's test was employed to verify data sphericity and the Greenhouse-Geisser correction was applied to correct $\mathrm{F}$ and $\mathrm{p}$-values when needed. To locate possible differences found in the ANOVA, the sequential $t$-test with False Discovery Rate (Benjamini \& Hochberg, 1995) was used as a post-hoc test. This multiple comparison correction was chosen for having more power compared to standard corrections such as Bonferroni's.

The significance level was set as $\alpha<.05$. Data organization, analysis and plotting was made using the $\mathrm{R}$ software environment for statistical computing (R Core Development Team., 2013).

\section{Results}

A statistical detectable difference was found only for the Body Position factor, F $(2,36)=13.07$, $p<.01, \eta^{2} \mathrm{G}=0.15$, with no detectable effects either for the Groups factor, $F(1,18)=1.82, \mathrm{p}>.05$, or the Group vs. Body Position interaction, $\mathrm{F}(2,36)=0.16$, $\mathrm{p}>.05$, indicating $\mathrm{OB}$ and $\mathrm{EU}$ group's reaction time performance was similar for each body position. Figure 1 shows means plus three standard deviations for reaction times (in milliseconds) for both groups in the three body positions, illustrating the comparable performance between both groups in each body position (sitting, bipedal standing and monopedal standing).

Post-hoc analysis for the Body Position factor located the differences between the sitting vs. mono-

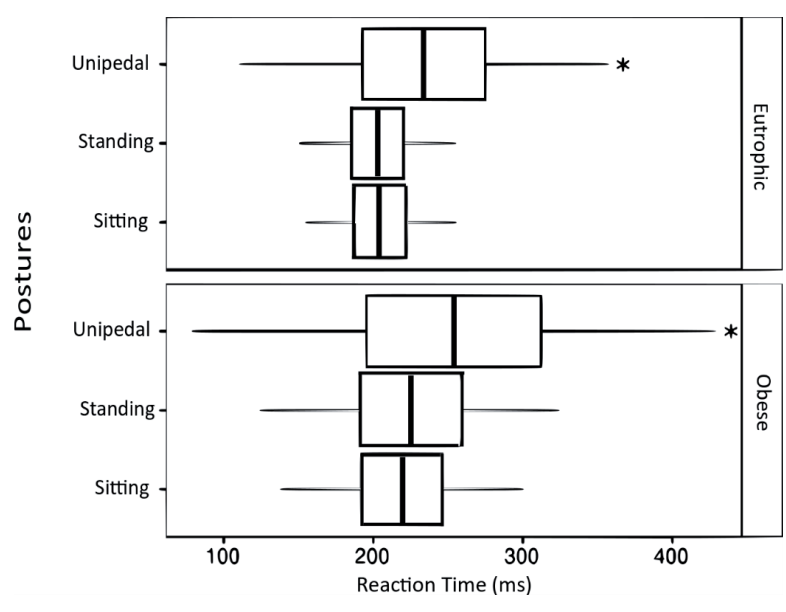

Note. * Denotes statistically significant difference between the unipedal and the other two body positions.

Figure 1. Boxplots (mean and standard deviations) of reaction time (in milliseconds) of participants in $O B$ and EU groups, in the three different body positions (sitting, standing and unipedal standing).

pedal, and bipedal standing vs. monopedal conditions. These results reveal that the attention demand needed to maintain postural control, as measured by its influence on the reaction time, was similar for the sitting and bipedal standing positions, whereas the monopedal standing showed a higher reaction time compared to the other two conditions.

\section{Discussion and conclusions}

The aim of the present study was to investigate if obesity, identified by the WHO (2015) classification, affects the attention allocation for postural control. The visual reaction time, concurrent with the support of body positions with differing balance exigence levels, was employed to infer about the attentional demands of obese and eutrophic individuals. The study's results showed that obesity did not affect the attention allocation regardless of body position, i.e., in spite of the varying demands of postural control. This result partially confirms our initial hypothesis, as no differences between the groups were revealed in reaction time in everyday usual body positions, sitting and bipedal standing. Conversely, we expected differences between the groups while sustaining the body position with the greatest degree of instability - monopedal standing - corroborating previous findings (Mignardot, et al., 2010), but that did not occur.

In a recent study, Yi et al. (2014) evaluated the body balance of obese and eutrophic individuals using the Balance Error Scoring System (BESS), a test that simulates postural control activities similar to those performed in everyday life. The results showed that BMI did not influence the body balance, which was corroborated with the findings of the present study. It is possible that, although obese individuals have greater oscillation in their 
center of pressure in maintaining balance (Hue, et al., 2007; McGraw, et al., 2000; Teasdale, et al., 2006), this variation may not be enough to increase the demand for attention necessary to the postural control in daily body positions. However, considering that the position of greater postural instability in our study (monopedal) presented results out of line with the study conducted by Mignardot et al. (2010), we must consider possible factors that led to this divergence.

A possible explanation may involve the type of stimulus and response used to measure reaction time. While the present study employed visual stimuli with manual responses, the study by Mignardot et al. (2010) presented auditory stimuli and recorded vocal responses. Differences in visual to auditory performances in reaction time are well known in the field, with faster reaction times to sound stimuli (Welford, 1980). Nevertheless, if one of these stimuli (or even the type of response) allows better allocation of the attention needed to maintain the obese and eutrophic posture is a question still to be investigated. In addition, it is possible that the participants' sex may have affected the observed results, since the study of Mignardot et al. (2010) evaluated performance in individuals of both sexes and our study had only women as participants. Two factors may have contributed to the difference between the studies, concerning the participants' sex: biases in reaction time and body fat distribution. Regarding the first factor, a study evaluating 7130 individuals' reaction times - a very large sample - in different age groups revealed no sex disparities in a reaction time task, similar to the employed in the present study (Der \& Deary, 2006). Therefore, the difference between the two studies could not be ascribed to sex differences in reaction time. Regarding the body fat distribution, evidence suggests it tends to follow a pattern according to sex (Wiklund, et al., 2008), as men usually accumulate fat mass in the abdomen and women amass body fat in the hips region. Although these distribution patterns could suggest different effects on balance, this association remains debatable (Capodaglio, Cimolin, Tacchini, Parisio, \& Galli, 2012). In this sense, future studies could assess and control body fat distribution, to investigate possible effects on both the attention allocation and balance while performing another (dual) task.
Other possible explanation for the difference between previous results by Mignardot et al. (2010) and our study refers to the experimental environment and the instruction provided. The former study employed a force platform and instructed participants to avoid body swaying as much as possible, while no similar instruction was provided in the present study as it could impair performance in the reaction time task. These divergent results suggest the instruction may have influenced the participants' motor control mechanisms (McNevin, et al., 2003; Natafi \& Vuillerme, 2013; Wulf, Shea, \& Park, 2001; Wulf \& Prinz, 2001), aggravating the control problems of obese individuals. However, the possible influence of the "avoid swaying as much as possible" instruction in the attention allocation is a problem that remains to be investigated in future studies.

Regarding the different body positions evaluated, the monopedal position was the only one in which significant differences in reaction time performance were found for both groups. The slower reaction times indicate that the more unstable position requires greater attentional resources compared to the bipedal standing and sitting body positions. This result agrees with other previous findings in which reaction times changed due to postural instabilities and different body positions (Lajoie, et al., 1993). Still, our evidence does not agree completely with the previous studies' results. The mentioned study evaluated the reaction time performance of six eutrophic participants in seated and standing with feet together body positions. The study found the differences in reaction times between the two positions, not detected in the present study. As discussed above in the differences between the study by Mignardot et al. (2010) and ours, the effect found may be attributed to the stimuli and response types employed, as the Lajoie et al. (1993) study also utilized sound stimuli and vocal reaction to measure reaction times. Hence, the relation between different stimulus / response types and the inference of the attention allocation in dual-task paradigm balance studies remains open to investigation.

The results of the present study showed that body positions with greater instability, such as the monopedal support, demand more attentional resources to support the postural control, compared to more stable positions as sitting and bipedal standing. In addition, our findings diverge from previous studies as no effect of obesity on attentional demand for postural control was found.

\section{References}

Benjamini, Y., \& Hochberg, Y. (1995). Controlling the false discovery rate: A practical and powerful approach to multiple testing. Journal of the Royal Statistical Society. Series B (Methodological), 57(1), 289-300.

Brown, L.A., Sleik, R.J., \& Winder, T.R. (2002). Attentional demands for static postural control after stroke. Archives of Physical Medicine and Rehabilitation, 83(12), 1732-1735. doi: 10.1053/apmr.2002.36400 
Capodaglio, P., Cimolin, V., Tacchini, E., Parisio, C., \& Galli, M. (2012). Balance control and balance recovery in obesity. Current Obesity Reports, 1(3), 166-173. doi: 10.1007/s13679-012-0018-7

Der, G., \& Deary, I.J. (2006). Age and sex differences in reaction time in adulthood: Results from the United Kingdom Health and Lifestyle Survey. Psychology and Aging, 21(1), 62-73. doi: 10.1037/0882-7974.21.1.62

Gage, W.H., Sleik, R.J., Polych, M.A., McKenzie, N.C., \& Brown, L.A. (2003). The allocation of attention during locomotion is altered by anxiety. Experimental Brain Research, 150(3), 385-394.

Hue, O., Simoneau, M., Marcotte, J., Berrigan, F., Doré, J., Marceau, P., \& Teasdale, N. (2007). Body weight is a strong predictor of postural stability. Gait and Posture, 26(1), 32-38. doi: 10.1016/j.gaitpost.2006.07.005

Kopelman, P.G. (2000). Obesity as a medical problem. Nature, 404(6778), 635-643. doi: 10.1038/35007508

Lajoie, Y., Teasdale, N., Bard, C., \& Fleury, M. (1993). Attentional demands for static and dynamic equilibrium. Experimental Brain Research, 97(1), 139-144. doi: 10.1007/BF00228824

McGraw, B., McClenaghan, B.A., Williams, H.G., Dickerson, J., \& Ward, D.S. (2000). Gait and postural stability in obese and nonobese prepubertal boys. Archives of Physical Medicine and Rehabilitation, 81(4), 484-489. doi: 10.1053/mr.2000.3782

McNevin, N.H., Shea, C.H., \& Wulf, G. (2003). Increasing the distance of an external focus of attention enhances learning. Psychological Research, 67(1), 22-29. doi: 10.1007/s00426-002-0093-6

Mignardot, J.B., Olivier, I., Promayon, E., \& Nougier, V. (2010). Obesity impact on the attentional cost for controlling posture. PLoS ONE, 5(12), e14387. doi: 10.1371/journal.pone.0014387

Natafi, G, \& Vuillerme, N. (2013). Decreasing internal focus of attention improves postural control during quiet standing in young healthy adults. Research Quarterly for Exercise and Sport, 82, 634-43.

R Core Development Team. (2013). R: A language and environment for statistical computing (Version 3.0.2). Vienna, Austria: R Foundation for Statistical Computing.

Teasdale, N., Hue, O., Marcotte, J., Berrigan, F., Simoneau, M., Doré, J., ..., \& Tremblay, A. (2006). Reducing weight increases postural stability in obese and morbid obese men. International Journal of Obesity, 31(1), 153-160. doi: $10.1038 /$ sj.ijo.0803360

Tucker, M.G., Kavanagh, J.J., Barrett, R.S., \& Morrison, S. (2008). Age-related differences in postural reaction time and coordination during voluntary sway movements. Human Movement Science, 27(5), 728-737. doi: 10.1016/j. humov.2008.03.002

van Dieën, J.H., Koppes, L.L.J., \& Twisk, J.W.R. (2010). Postural sway parameters in seated balancing: Their reliability and relationship with balancing performance. Gait and Posture, 31(1), 42-46. doi: .org/10.1016/j. gaitpost.2009.08.242

Vuillerme, N., Isableu, B., \& Nougier, V. (2005). Attentional demands associated with the use of a light fingertip touch for postural control during quiet standing. Experimental Brain Research, 169(2), 232-236. doi: 10.1007/ s00221-005-0142-7

Welford, A.T. (1980). Reaction times. Academic Press.

Wiklund, P., Toss, F., Weinehall, L., Hallmans, G., Franks, P.W., Nordström, A., \& Nordström, P. (2008). Abdominal and gynoid fat mass are associated with cardiovascular risk factors in men and women. The Journal of Clinical Endocrinology and Metabolism, 93(11), 4360-4366. doi: 10.1210/jc.2008-0804

WHO - World Health Organization. (2015). A report about obesity. Retrieved from http://www.who.int/topics/obesity/ en/ on May 1, 2015.

Wulf, G., \& Prinz, W. (2001). Directing attention to movement effects enhances learning: A review. Psychonomic Bulletin and Review, 8(4), 648-660.

Wulf, G., Shea, C., \& Park, J.H. (2001). Attention and motor performance: Preferences for and advantages of an external focus. Research Quarterly for Exercise and Sport, 72(4), 335-344.

Yi, L.C., Neves, A.L. S., Areia, M., Neves, J.M.O., Souza, T.P., \& Caranti, D.A. (2014). Influência do índice de massa corporal no equilíbrio e na configuração plantar em obesos adultos. [Influence of body mass index on balance and plantar configuration in obese adults. In Portuguise.]. Revista Brasileira de Medicina do Esporte, 20(1), 70-73.

Submitted: November 20, 2017

Accepted: February 14, 2019

Published Online First: November, 27, 2019
Correspondence to:

Fernando Garbeloto dos Santos, Ph.D.

School of Physical Education and Sport, University of São Paulo.

Professor Mello Moraes 65, São Paulo, Brazil.

Zip Code: 05508-030

e-mail: fegarbeloto@gmail.com

\section{Funding}

This research and FGS were funded by CAPES (Ministry of Education - Brazil) [88881.189575/2018-01]. 